\title{
Tensões e diálogos entre acadêmico e popular: a Coleção Renato Miguez
}

Carolina Rodrigues de Lima

DOI 10.20396/eha.vi14.3414

No decorrer do séc. XX, os estudos dedicados à cultura popular brasileira se desenvolveram sob a égide do Movimento Folclórico Brasileiro. Uma estrutura bem organizada e articulada por muitas décadas, acompanhou a institucionalização dos estudos folclóricos, destacando-se a criação e solidificação de instituições federais como o Centro Nacional de Folclore (1947), a Campanha de Defesa do Folclore Brasileiro (1958), o Instituto Nacional do Folclore (1976) e, mais recentemente, o Centro Nacional de Folclore e Cultura Popular (2003), em vigor até os dias atuais. Pertencentes a diferentes órgãos governamentais durante sua trajetória, essas instituições foram responsáveis pela elaboração de congressos, organização e fomento de pesquisas, além da coleta de enormes acervos bibliográficos e museológicos.

Apesar do sucesso na criação de agências estatais dedicadas à preservação da cultura popular, os folcloristas não obtiveram êxito na implantação de espaços dedicados aos estudos do folclore nas universidades. De acordo com Vilhena, "[...] no plano dos estereótipos, o folclorista se tornou o paradigma de um intelectual não acadêmico ligado por uma relação romântica ao seu objeto, que se estudaria a partir de um colecionismo incontrolado e de uma postura empiricista" ${ }^{\prime 2}$. É interessante observar que essa desvalorização acadêmica se deu de forma específica no Brasil, a despeito das origens históricas desse campo de estudos, em contexto europeu, estarem relacionadas ao direcionamento das preocupações eruditas à cultura popular e principalmente por sua relação com a identidade nacional ${ }^{3}$.

Nos debruçamos, então, ao contexto específico da Escola de Belas Artes da UFR], onde, a partir de um caso específico, podemos ter um breve panorama da inserção que os estudos sobre arte e cultura popular tiveram na instituição. A trajetória da Coleção Renato Miguez de Arte Popular nos revela o indivíduo ligado à rede de intelectuais pertencentes ao Movimento Folclórico Brasileiro que também estava inserido na universidade, lecionando e produzindo pesquisas.

\footnotetext{
1 Bacharel em História da Arte pela Escola de Belas Artes da Universidade Federal do Rio de Janeiro (EBA/UFRJ) e mestranda em Artes Visuais, na linha de pesquisa Imagem e Cultura pelo Programa de Pós-Graduação em Artes Visuais da UFR]. Bolsista de mestrado CNPq.

2 VILHENA, 1997, p. 22

3 BURKE, 1989, p. 31.
} 
Nascido na cidade de Maceió em 1929, Renato Braga de Miguez Garrido ingressa em 1948 no curso de Escultura da Escola Nacional de Belas Artes, então vinculada à Universidade do Brasil, no Rio de Janeiro. É nessa instituição que constrói sua carreira profissional, sendo admitido como professor adjunto a partir de 1956 no curso de Escultura, lecionando até 1991, quando se aposenta como professor da disciplina de Folclore. Enquanto aluno, também atua profissionalmente como escultor, recebendo diversas encomendas e participando de salões de arte. Durante sua trajetória, se interessa pela cultura popular, especialmente por esculturas, reunindo por várias décadas uma coleção que hoje conta com 1366 itens de grande variedade. Composta majoritariamente por peças em cerâmica de arte popular brasileira, a coleção conta também com obras de arte indígena, de arte popular de origem europeia, africana e de países da América Latina, além de uma fotografia e artefatos variados.

As atividades documentadas de Renato Miguez coincidem com um período histórico no qual as discussões a respeito da cultura popular estão no centro de muitos debates sobre patrimônio, principalmente com a criação de instituições destinadas ao apoio e proteção. Herança do governo Vargas, principalmente no período do Estado Novo, um projeto de nação pautada na homogeneidade cultural visava a construção de uma identidade nacional, e para isso, a elaboração de narrativas que representassem o povo se legitimava enquanto estratégia de fortalecimento do poder político ${ }^{4}$.

Durante o longo processo de institucionalização do que se entendia por folclore e cultura popular, as percepções sociais do povo brasileiro (direcionadas principalmente à classe pobre e trabalhadora) por parte de uma elite social e intelectual foram se consolidando. Segundo Guacira Waldeck, "[...] a atividade de estudiosos e artistas, assim como iniciativas institucionais no sentido de constituir o Folclore como campo de estudos envolve, paralelamente, a coleta e a criação de acervos"s. As identidades, considerando sobretudo origens geográficas e de classe, são criadas através de representações sociais que se expressam na materialidade dos objetos.

A formação da Coleção Renato Miguez de Arte Popular acompanha as pesquisas do colecionador e é por elas motivada. Em entrevista ${ }^{6}$, as irmãs de Renato Miguez, que ficaram responsáveis por todo o processo de guarda, proteção e doação da coleção após o falecimento do colecionador, relatam que ele costumava fazer viagens frequentes a algumas cidades do nordeste brasileiro hoje

\footnotetext{
4 DIAS, 2005, p. 71

5 WALDECK, 2008, p. 13.

6 Entrevista semiestrutural a Merisa Miguez e Irene Miguez realizada por Carolina Rodrigues e Carla Dias, em sua residência, em 13 de julho de 2015 .
} 
famosas por sua considerável produção de arte popular, como a região do Alto do Moura, em Pernambuco. Nesses locais, realiza pesquisas de campo que mais tarde dariam origem a importantes publicações. Segundo sua irmã, Merisa Miguez, costumavam ir de carro para essas cidades e voltavam com as bagagens repletas de esculturas em cerâmica.

Ainda como professor da cadeira de modelagem no curso de Escultura na ENBA, em 1960, Renato Miguez recebe uma bolsa pela Association Internacionale de Arts Plastiques, para a qual concorreu com a escultura, para estudar técnicas em vidro por um ano em Praga, na Tchecoslováquia, embarcando em 23 de novembro 1961. Combinou seus estudos práticos com pesquisas em arte popular europeia, enquanto adquiria novas peças para sua coleção ${ }^{7}$. Após um ano em Praga, Miguez foi para Portugal onde renovou seu passaporte especial de estudante para continuar na Europa. Visitou países da então "Cortina de Ferro", como Alemanha Oriental, União Soviética e Polônia, sempre interessado nas manifestações culturais da escultura popular. Também visitou Suíça, Bélgica, Itália, Espanha e França, onde frequentou o Curso de Arte Popular no Museu do Homem em Paris durante mais um ano e proferiu uma palestra sobre arte popular brasileira, com foco em cerâmica, utilizando como material didático alguns slides que já tinha reunido, provavelmente por já estar pesquisando esse tema no Brasil e ter começado a reunir peças para sua coleção. Retornou ao Brasil em março de 1963. Na ocasião de seu retorno, um jornal da época ${ }^{8}$, publica o seguinte artigo:

Retornou há pouco, da Europa, o jovem escultor Renato Miguez, que visitou a TchecoEslováquia e outros países da Cortina de Ferro, com bolsa de estudos. Depois, sem auxílio de ninguém, Miguez percorreu diversos países, em todos realizando conferências e seguindo cursos de especialização de sua grande paixão - o folclore. O que é mais: trouxe, para instituições culturais brasileiras, catálogos e livros dos museus que visitou, bem como propostas de convênio entre museus europeus e brasileiros. Quando se pensa em tantos bolsistas que daqui saem a pêso de dólar e do exterior não enviam nem lembranças, temos vontade de pedir para Renato Miguez a Ordem do Cruzeiro do Sul. Trata-se, positivamente, de alguém que merece respeito.

A partir dessa publicação, é possível perceber a abrangência da rede de relações na qual o colecionador estava inserido, entendendo também que o processo de colecionismo não se constitui apenas como uma prática individual e fetichista, mas como um verdadeiro projeto, cuja coleta das peças era apenas um índice. Os ideais nacionalistas do pesquisador se expressam por vezes em seus

7 Obtive, através de Merisa Miguez, a cópia dos passaportes utilizados pelo escultor na ocasião da viagem, possibilitando traçar uma trajetória percorrida por ele na Europa, combinando as informações contidas no documento com os relatos de suas irmãs.

8 Pequena cópia de um recorte de jornal, sem data ou referência, cedida ao Museu D. João VI pelas irmãs do colecionador. 
artigos ou entrevistas que concede à imprensa.

A trajetória de Renato Miguez, intrinsecamente ligada à cultura popular, não poderia deixar de fora uma relação com o carnaval. O primeiro registro oficial de sua participação nos festejos cariocas se dá no dia 28 de fevereiro de 1954, quando participa da comissão julgadora do desfile das escolas de samba do Grupo I ${ }^{9}$. A Galeria do Samba ${ }^{10}$ também indica sua participação como julgador de vestuário do desfile preliminar em 1961.

Sua primeira grande participação na organização de um desfile se dá em 1966. Um artigo escrito por Harry Laus, intitulado "Folclore no Carnaval", para o Jornal do Brasil em 4 de março de 1966, apresenta Renato Miguez como um escultor estudioso do folclore brasileiro. A publicação apresenta o enredo sugerido pelo escultor à Escola de Samba São Clemente, fugindo dos temas históricos já muito explorados nos anos anteriores e fixando em aspectos da tradição popular. Responsável pelos desenhos e por supervisionar os trabalhos de construção de carros, figurinos e outros arranjos utilizados no desfile, o Miguez considera ser possível representar o folclore brasileiro em toda sua grandiosidade e riqueza de cores e formas, além da beleza dos ritmos e diversidade dos temas. Falando da ideia do enredo, comenta:

Admitimos a formação brasileira originada de três raças. Partindo do branco, o português, dele herdamos parte de nossas danças e indumentárias. Do índio, os donos da terra, herdamos as mais lindas lendas e os mais lindos contos. Dos negros africanos veio a ampliação e edificação de nossa música que mais adiante tomariam características puramente brasileiras, como é o caso do samba. Além disto nos trouxeram os negros uma variedade enorme de instrumentos que junto aos dos brancos apresentam essa variedade de sons que caracterizam nossa batucada. Por fim, ainda dos pretos, recebemos crendices e superstições que somadas às dos índios e brancos colocam nosso folclore como um dos mais punjantes do mundo.

O entendimento do povo e, consequentemente, da cultura brasileira como originária das três raças - negra/africana, indígena e branca/portuguesa - apesar de ser datado e problematizado nos tempos atuais, nos fornece dicas dos ideais que guiaram o processo de formação da coleção. Ao observar a diversidade desse acervo, é possível perceber a preocupação de reunir esses três pilares da formação étnica brasileira. Entendendo essas peças como representações, podemos exemplificar com a presença contundente dos galos de Barcelos como um dos símbolos da cultura portuguesa,

\footnotetext{
9 COSTA, 2000, p. 227

10 Site que reúne informações documentais e esquematizadas sobre todas as escolas de samba. Disponível em: http://www.galeriadosamba. com.br/carnaval/1961/julgadores/. Acesso em 27 Mar. 2019.
} 


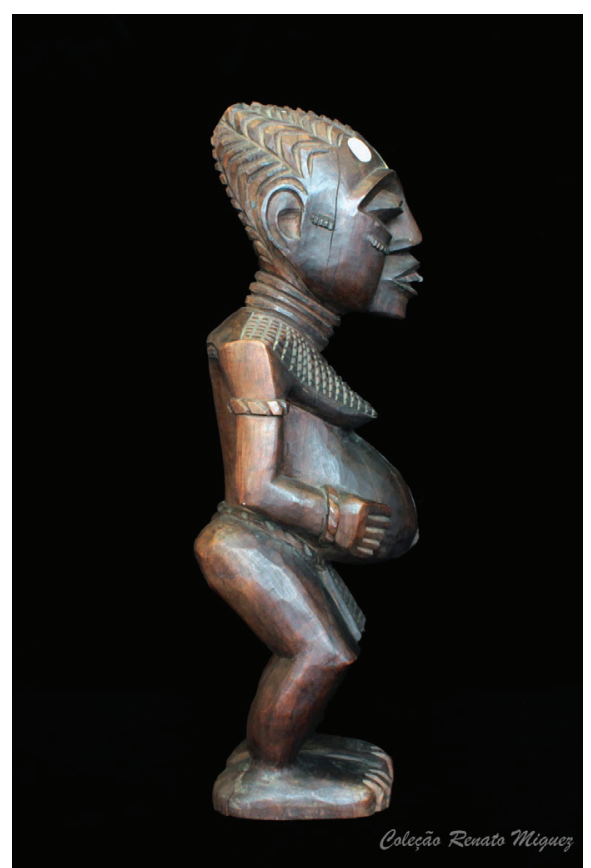

[Figura 1] Escultura africana.

Fonte: Acervo do Museu D. João VI, Coleção Renato Miguez de Arte Popular. Foto: Gabrielle Nascimento.

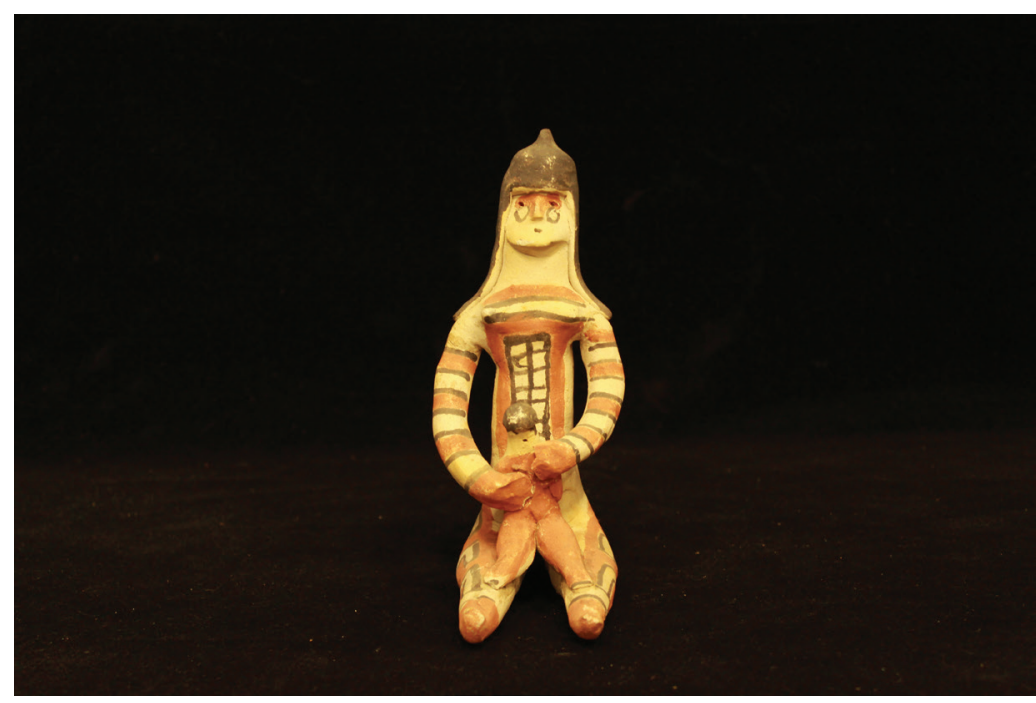

[Figura 2] Boneca Karajá (Ritxoko).

Fonte: Acervo do Museu D. João VI, Coleção Renato Miguez de Arte Popular. Foto: Gabrielle Nascimento.
[Figura 3]

Coleção Renato Miguez de Arte Popular, ainda na residência do colecionador. Fonte: Fotografias cedidas por Merisa e Irene Miguez.

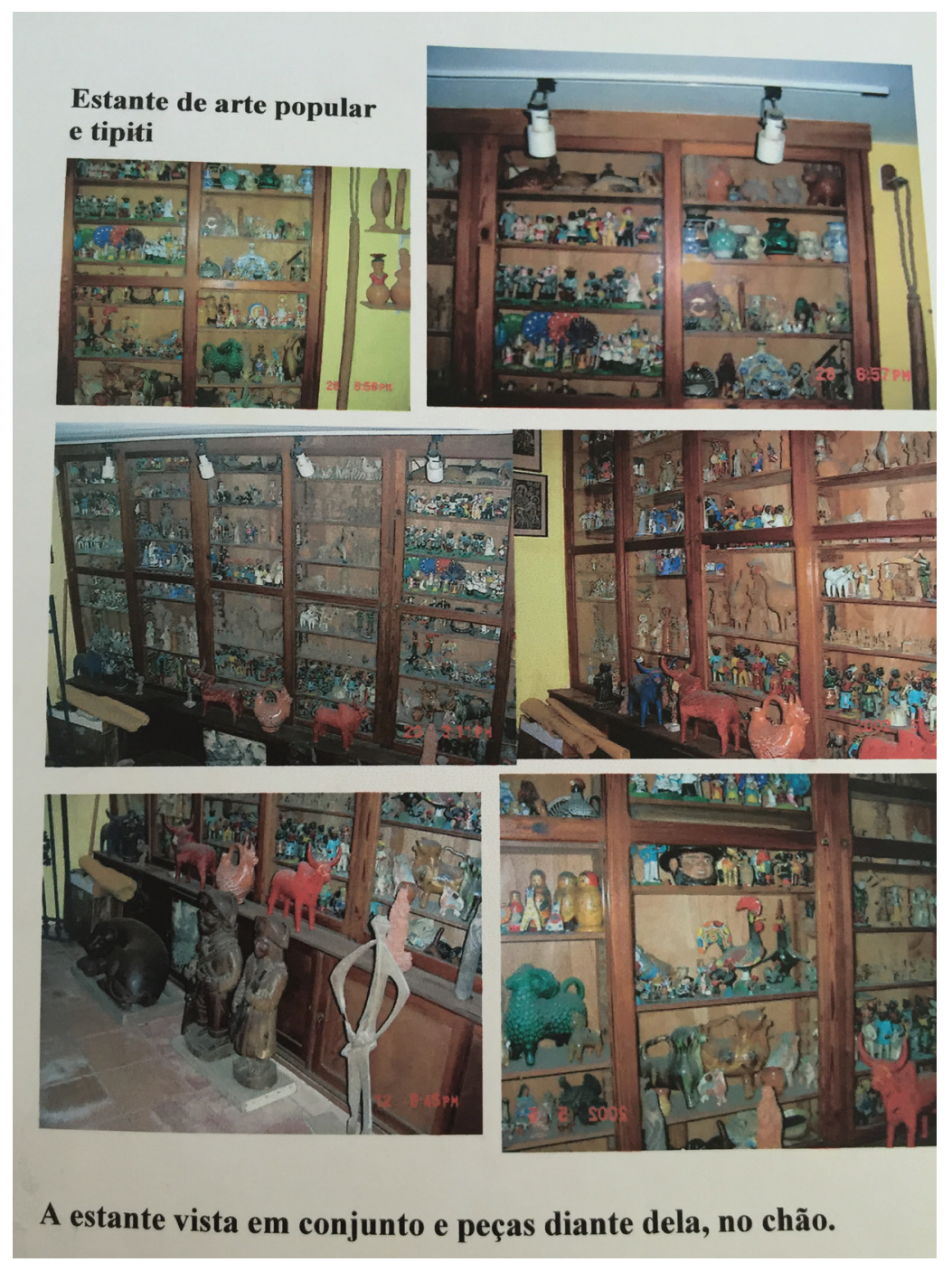


grandes esculturas em madeira de origem africana (Figura 1) e as bonecas Karajá (Ritxoko) trazendo as culturas indígenas (Figura 2).

A coleção Renato Miguez de Arte Popular, durante toda sua trajetória, se faz presente em diversas esferas, sendo reunida em torno do indivíduo, participando ocasionalmente de atividades externas ligadas a instituições e, por fim, se estabelecendo como parte do acervo do um Museu D. João VI. Nos termos de Krzysztof Pomian, uma possível definição de coleção seria "conjunto de objetos naturais ou artificiais, mantidos temporária ou definitivamente fora do circuito das atividades econômicas, submetidos a uma proteção especial e expostos ao olhar"11. Essa definição, segundo o autor, teria um caráter universal, sendo aplicada tanto em coleções particulares quanto em coleções pertencentes a instituições museológicas.

Após o falecimento de Renato Miguez, em 2002, sua casa permaneceu fechada por quase dez anos, sendo apenas administrada por suas irmãs Merisa e Irene Miguez até que se iniciasse o processo de doação, conservando a disposição das peças como deixadas pelo colecionador. Através do acesso às imagens (Figura 3) da coleção cedidas pelas irmãs, é possível identificar em que medida as características descritas por Pomian podem orientar essa coleção enquanto mantida em âmbito privado.

Organizada em armários com portas de vidro e em prateleiras, com luminárias direcionadas para as peças, a coleção se coloca ao dispor do olhar do espectador, de forma similar à expografia que pode ser encontrada em museus etnográficos, mesmo estando armazenadas em ambiente privado. Essa organização não é ingênua, mas fruto de uma intenção, a materialização de uma ordem particular que indica não somente o fascínio provocado por essas obras tanto em termos plásticos quanto em sua capacidade de representação, mas também o intenso trabalho de pesquisa a ela relacionado. Essa coleção se constitui também como uma biografia, uma prova material de todo uma trajetória de vida que, além de possibilitar a formação da coleção, também foi por ela motivada.

A partir da observação dessa imagem, a única disponível na qual, atualmente, podemos testemunhar a maior parte da coleção reunida em exposição, é possível ter um panorama da complexidade e diversidade da qual é composta, compreendendo o longo processo de institucionalização que ainda hoje se desenha no Museu D. João VI.

Em fevereiro de 2012, o Museu D. João VI, museu universitário pertencente à Escola de Belas Artes da Universidade Federal do Rio de Janeiro, recebe a doação de Merisa Miguez e Irene Miguez,

11 POMIAN, 1984, p. 55 
incorporando a Coleção Renato Miguez de Arte Popular ao seu acervo. Todo o processo de doação, recepção, incorporação e tombamento da coleção é supervisionado e mediado pela então coordenadora do museu, a antropóloga e professora da EBA Carla Dias.

Reunindo mais de 200 anos da história do ensino da arte no Brasil, o museu abriga coleções que tanto servem de referência para a formação de artistas e restauradores, quanto promovem reflexões e fornecem elementos para análises e pesquisas, auxiliando na formação de artistas, historiadores da arte e pesquisadores da Escola de Belas Artes e mesmo de fora da instituição.

Traçando um panorama histórico, o Museu D. João VI indica suas origens com um acervo que já era presente antes de sua criação, desde a Academia Imperial de Belas Artes, em que existia um museu que servia de apoio ao ensino da arte, e foi acrescido da coleção particular de Joachim Lebreton, e continuada com peças produzidas pela escola e provenientes de doações. Em 1937, com a criação do Museu Nacional de Belas Artes, o acervo foi dividido. O acervo que ficou relegado à escola, que viria a ser o Museu D. João VI, foi ainda acrescido com doações, como a Coleção Ferreira das Neves, além continuar incorporando obras acadêmicas ${ }^{12}$.

De acordo com José Reginaldo Gonçalves, tanto em seus usos sociais quanto em sua reclassificação como itens de coleção, peças de acervo museológico ou patrimônio cultural, objetos materiais sempre existirão como parte integrante de sistemas classificatórios. Segundo o antropólogo, "esta condição Ihes assegura o poder não só de tornar visíveis e estabilizar determinadas categorias socio-culturais, demarcando fronteiras entre estas, como também o poder, não menos importante, de constituir sensivelmente formas específicas de subjetividade individual e coletiva”³.

Os museus são lugares privilegiados para a alfabetização visual e são também espaços totalizadores, onde vários discursos podem ser construídos através do que se guarda e o que se expõe. 0 colecionamento é uma prática indissociável dos museus, é através dele, que se constitui o corpo edificado, materializado da instituição ${ }^{14}$. Este ato ocorre através de uma perspectiva histórica, socialmente engendrada a por atores autorizados ou legitimados em ou por suas coleções. Percebendo a trajetória do Museu D. João VI como instituição intrínseca ao ambiente acadêmico, com a formação de suas coleções acompanhando a trajetória da Escola de Belas Artes da UFRJ e ocasionais doações externas, podemos dizer que a constituição de seu acervo nos revela uma orientação acadêmica, voltada para uma arte considerada erudita e eurocêntrica. Desse modo, podemos pensar o impacto

\footnotetext{
12 DIAS, 2013.

13 GONÇALVES, 2007, p. 8.

14 DIAS, 2005, p. 8.
} 
causado pela chegada de uma coleção que rompe com essa tradição, trazendo uma produção que privilegia um conhecimento não institucionalizado, embora reunida por um antigo professor da instituição.

Através dos levantamentos feitos nessa pesquisa sobre suas atividades, temos evidências da dedicação de Renato Miguez na incorporação de conhecimentos relacionados à cultura popular na Escola de Belas Artes, dedicando grande parte de sua trajetória a esse propósito. Em seu artigo sobre Severino de Tracunhaém, ao lamentar a grande exploração que o mercado exercia sobre os artistas populares, além da falta de valorização destes artistas e suas manifestações culturais, Miguez evidencia a importância de um museu comprometido com a produção de conhecimento e a aproximação com as referências populares:

[...] precisamos respeitar e dar o devido valor ao que é nosso, não criar museus com a finalidade apenas de mostruários, pois já está superado; é necessário que se criem centros de pesquisa para se estudar de perto esses assuntos e de assistir ao futuro artista erudito em suas finalidades de sentimento, para que possa ter inspiração em elementos ligados a seu país e em consequência a si próprio. ${ }^{15}$

O Museu D. João VI possui um papel fundamental dentro da Escola de Belas Artes, se assemelhando às bibliotecas como suporte para as referências que apoiam a formação dos artistas ${ }^{16}$, assumindo um compromisso fundamental com a pesquisa e a produção de conhecimento. Atendendo aos anseios do colecionador, a Coleção Renato Miguez de Arte Popular tem importância não só em dinamizar o acervo do museu, como também contribui para a diminuição das relações de poder que se fazem entre uma tradição eurocêntrica e a estética popular brasileira, democratizando o ambiente artístico acadêmico. 


\section{Referências}

BURKE, Peter. Cultura popular na Idade Moderna; Europa: 1500-1800. São Paulo: Companhia das Letras, 1989.

COSTA, Haroldo. 100 anos de Carnaval no Rio de Janeiro. Rio de Janeiro: Irmãos Vitale, 2000.

DIAS, Carla da Costa. De Sertaneja à Folclórica a trajetória das Coleções Regionais do Museu Nacional -1920/1950. Rio de Janeiro: UFR], EBA, PPGA V, 2005.

DIAS, Carla da Costa. O Museu D. João VI: a Construção de Histórias e Acervos. XXVII Simpósio Nacional de História. ANPUH: Natal, 2013.

GONÇALVES, José Reginaldo Santos. Antropologia dos objetos: coleções, museus e patrimônios Rio de Janeiro: Museu, memória e cidadania, 2007.

MICUEZ, Renato. Severino de Tracunhaem - um ceramista da zona canavieira. In: Brasil Açucareiro, 1971.

POMIAN, Krzysztof. "Coleções" In: Enciclopédia Einaudi, vol.1 - Memória/História.

Porto, Imprensa Nacional Casa da Moeda, pp 51-86. 1985.

VILHENA, Luís Rodolfo. Projeto e missão: o movimento folclórico brasileiro (1947-1964). Rio de Janeiro: Funarte/FGV, 1997. WALDECK, Guacira. Brasis revelados: 50 anos do Centro Nacional de Folclore e Cultura Popular. Rio de Janeiro: IPHAN, CNFCP, 2008. 